\title{
Protogynous Hermaphroditism in the Wrasse Choerodon azurio
}

\author{
Akinobu Nakazono* and Janny Dirk Kusen* \\ (Received September 17, 1990)
}

\begin{abstract}
The sexual pattern of a commercially important labrid fish Choerodon azurio was studied using specimens collected along the northern coast of Kyushu, Japan. Seventeen specimens collected on April 19, 1990, ranged from 164 to $315 \mathrm{~mm}$ in standard length. Specimens of $285 \mathrm{~mm}$ SL and larger were males and those smaller were females. Males were distinguishable from females by the following external appearances, i.e. squarish forehead, wider black band running obliquely on the side, reddish pectoral fin, more prominent iridescent blue spots on the latter half of the body, and deeper blue color of forehead and at the margin of caudal fin. Histological examinations of the gonads revealed that all of 6 males in the sample had secondary testes. It was concluded that Choerodon azurio is a protogynous hermaphrodite as well as many other labrid species. Although no primary males occur in the present specimens, it is necessary to study a larger number of specimens before concluding whether the species is a monandric or diandric protogynous hermaphrodite.
\end{abstract}

The relatively large labrid Choerodon azurio attains a maximum total length of $40 \mathrm{~cm}$. It belongs to the subfamily Bodianinae and is distributed in southern Japan, the Korean Peninsula, Taiwan and the China Seas." At the northern coast of Kyushu, Japan, it inhabits rocky reefs deeper than $15 \mathrm{~m}$ and a number of individuals are collected by gill nets, constituting a commercially important reef fish. As far as the present knowledge indicates, practically all species of labrids are protogynous hermaphrodites, ${ }^{2-4)}$ and it is expected that $C$. azurio is also a protogynous hermaphrodite. However, available data on the sexuality of the fish is scarce. It is only reported that male adults exhibit typical secondary sexual characters, especially squarish forehead. ${ }^{1)}$ The present study aimed to verify if this popular and commercially important reef fish is a protogynous hermaphrodite or not, as well as other members of the family, through histological examinations of the gonads. It also describes the size-sex relationship, dimorphism and dichromatism of C. azurio.

\section{Materials and Methods}

Seventeen specimens used in the present study were collected by gill net near Tsuyazaki $\left(33^{\circ} 47^{\prime} \mathrm{N}\right.$, $130^{\circ} 29^{\prime} \mathrm{E}$ ), northern coast of Kyushu, on April 19, 1990. Body sizes of the specimens ranged from 164 to $315 \mathrm{~mm}$ in standard length (SL). Soon after they were purchased at a fish market, a $40 \%$ formalin solution was injected into the abdominal cavity and the whole body was preserved in $10 \%$ formalin seawater. After the fish were thoroughly fixed, the standard length and the body weight were measured to the nearest $1 \mathrm{~mm}$ and $0.1 \mathrm{~g}$, respectively. Gonads were taken out and were weighed to the nearest $0.01 \mathrm{~g}$ and sexed by their external appearances. Gonado-somatic index $(\mathrm{GSI}=\mathrm{GW}(\mathrm{g}) \times 100 / \mathrm{BW}(\mathrm{g}))$ of each fish was calculated. All of the 6 testes and 6 out of 11 ovaries were used for histological examinations. The rest of ovaries were large and easily sexed by their external appearances. Transverse sections were cut at 5-7 $\mu \mathrm{m}$ thickness near the middle of longitudinally long gonads, following the routine paraffin method. The structure of the testes, i.e. primary or secondary, and developmental stages of the oocytes were examined under a microscope, after staining with Mayer's hematoxylin and eosin.

\section{Results}

Size Differences between the Sexes and Sexual Dimorphism

There was a clear size-sex relationship between Choerodon azurio specimens examined in the present study. Specimens of $285 \mathrm{~mm} \mathrm{SL}$ and larger were males and those smaller were females (Table 1). Not only size but also sexual dimorphism and dichromatism were apparent between the sexes. As stated above, the forehead is squarish in males by

* Department of Fisheries, Faculty of Agriculture, Kyushu University, Hakozaki, Fukuoka 812, Japan (中國明信, J. D. Kusen：九州大学燢学部水産学科)。 
Table 1. Sexual pattern of Choerodon azurio

\begin{tabular}{rllllll}
\hline No. & Std. length & Body wt. & Gonad wt. & GSI & Sex & $\begin{array}{c}\text { Body form \& } \\
\text { coloration }\end{array}$ \\
\hline $0419-1$ & $164 \mathrm{~mm}$ & $167.5 \mathrm{~g}$ & $0.77 \mathrm{~g}$ & 0.460 & $\mathrm{~F}$ & IP \\
-2 & 177 & 222.8 & 1.66 & 0.745 & $\mathrm{~F}^{*}$ & IP \\
-3 & 182 & 241.8 & 1.75 & 0.724 & $\mathrm{~F}^{*}$ & IP \\
-4 & 192 & 284.9 & 2.35 & 0.825 & $\mathrm{~F}^{*}$ & IP \\
-5 & 198 & 266.3 & 1.36 & 0.511 & $\mathrm{~F}^{*}$ & IP \\
-6 & 218 & 400.8 & 3.22 & 0.803 & $\mathrm{~F}^{*}$ & IP \\
-7 & 220 & 446.8 & 4.63 & 1.036 & $\mathrm{~F}$ & IP \\
-8 & 245 & 556.9 & 7.62 & 1.368 & $\mathrm{~F}$ & IP \\
-9 & 250 & 623.0 & 7.26 & 1.165 & $\mathrm{~F}$ & IP \\
-10 & 257 & 619.0 & 3.52 & 0.569 & $\mathrm{~F}^{*}$ & IP \\
-11 & 266 & 675.0 & 6.41 & 0.950 & $\mathrm{~F}^{*}$ & IP \\
-12 & 285 & 909.8 & 0.88 & 0.097 & $2^{\circ} \mathbf{M}^{*}$ & TP \\
-13 & 290 & 901.2 & 0.52 & 0.058 & $2^{\circ} \mathbf{M}^{*}$ & TP \\
-14 & 295 & 1028.8 & 2.60 & 0.253 & $2^{\circ} \mathbf{M}^{*}$ & TP \\
-15 & 300 & 1115.1 & 1.85 & 0.166 & $2^{\circ} \mathbf{M}^{*}$ & TP \\
-16 & 305 & 1159.9 & 2.69 & 0.232 & $2^{\circ} \mathbf{M}^{*}$ & TP \\
-17 & 315 & 1270.3 & 2.87 & 0.226 & $2^{\circ} \mathrm{M}^{*}$ & TP \\
\hline
\end{tabular}

GSI $=$ Gonad wt. $(\mathrm{g}) \times 100 /$ Body wt $(\mathrm{g}), \mathrm{F} ;$ Female, $2^{\circ} \mathrm{M}$ : Secondary male, IP: Initial phase, TP: Terminal phase. Asterisk shows that the gonad was examined histologically.

swelling of the flesh, but gently-sloping in females. A black band running obliquely on the side is wider in males. Pectoral fins are reddish in males but yellowish in females. Iridescent blue spots scattered on the latter half of the body are more prominent in males. Blue color of forehead and at the margin of caudal fin is deeper in males. Sexual dimorphism and dichromatism are known in many protogynous labrid species studied so far. ${ }^{2-x}$ The body form and color observed in larger males of labrids are referred to as terminal phase. As shown in Table 1, all males were differently colored from females and were in the terminal phase.

\section{Gonadal Structure and Sex Change}

Ovary: Spawning season of $C$. azurio is not known, but the results of the study ${ }^{s)}$ on reproductive behaviors of other temperate labrid species suggest that the present species spawns in summer months as well. The present specimens were collected in April when the fish were supposed to be reproductively inactive. The female GSI was $0.832 \pm 0.280$ (mean and $\mathrm{SD}, \mathrm{n}=11$ ) and it also indicated that the fish were not in spawning season (Table 1).

According to histological observations, the small ovaries of $C$. azurio were in the young developmental stages. Most of the oocytes were in the perinucleolus stage, and oocytes in the yolk stages did not occur (Fig. 1-A). The larger number of oocytes suggested that most of these females would become sexually functional in the coming spawning season. The rest of the ovaries, which were not examined histologically, were large in volume and oocytes were visible with the naked eye. It was also suggested that they would become functional in the coming spawning season.

Testis: One of the characteristics of testicular structure found in the labrid fishes is that the testis shows previous gonadal status. On sex change, ovarian tissues degenerate leaving ovarian wall, and testicular tissues start to develop at the same place as ovarian lamellae. For this reason, testes transformed from ovaries have the structure corresponding to a former ovarian wall and an ovarian lumen. This type of testes are referred to as secondary testes..,33 Such structure is not seen in testes of primary males.

All the males of the present specimens exhibited the following features; a larger lumen corresponding to the former ovarian cavity and a thin membrane in the place of former ovarian wall (Fig. 1-B). The secondary structure found in C. azurio was fundamentally the same as that of many other labrid species, ${ }^{2-3)}$ and indicated that these males were derived from females by sex change. It is known in other protogynous species that the secondary structure of the testis disappears soon after a female has changed into a male. ${ }^{\text {a) }}$ In the present specimens, the secondary structure was evident even in the largest specimen. It seems 


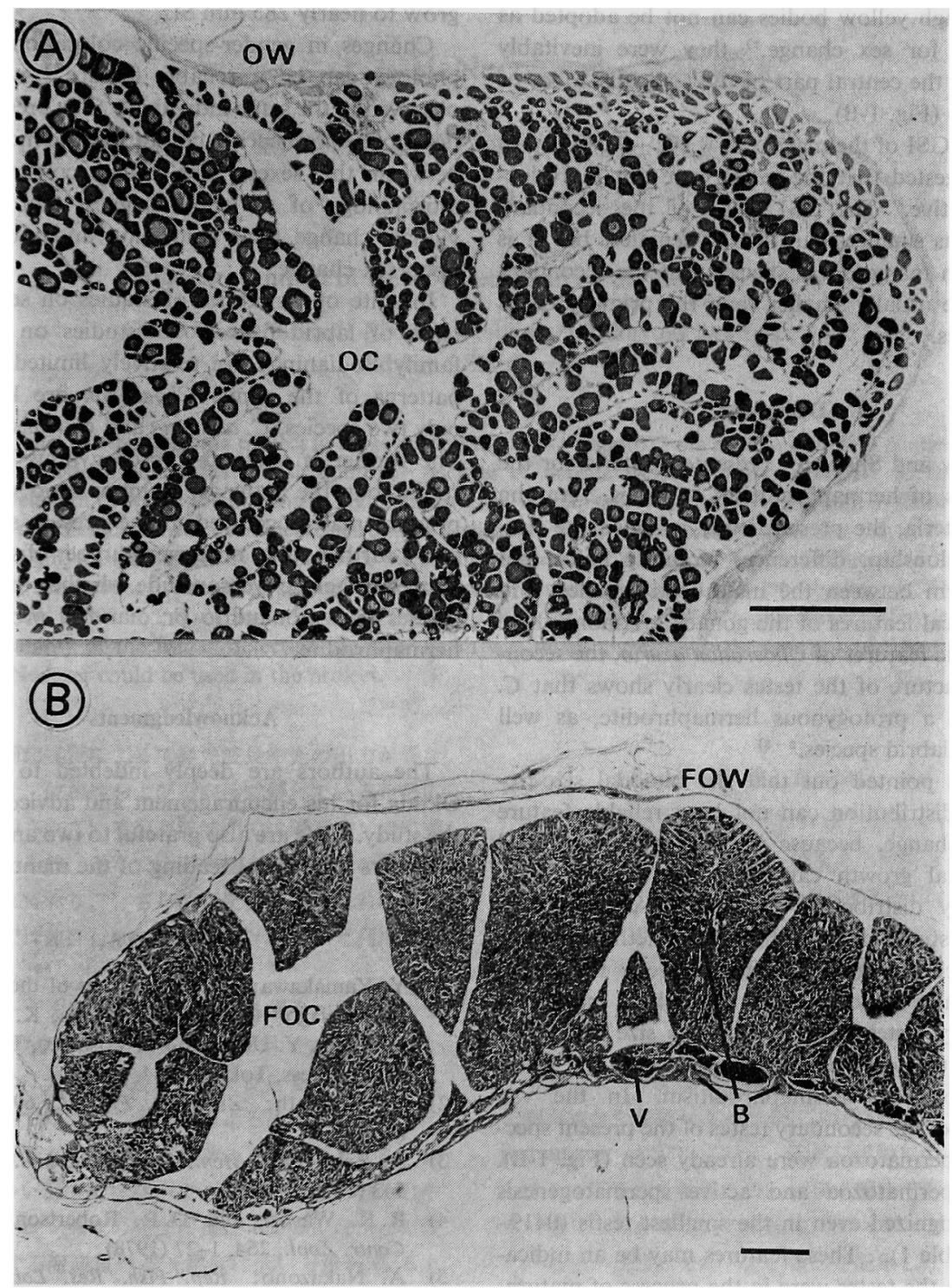

Fig. 1-A. Photomicrograph of a transverse section of the ovary in Choerodon azurio, showing most of oocytes are in the perinucleolus stage. $257 \mathrm{~mm} \mathrm{SL}$. Date 900419 . OW=Ovarian wall; $\mathrm{OC}=$ Ovarian cavity. Scale bar represents $0.5 \mathrm{~mm}$.

Fig. 1-B. Photomicrograph of a transverse section of the testis in Choerodon azurio, showing secondary structure. $295 \mathrm{~mm} \mathrm{SL}$. Date 900419. FOW=Former ovarian wall; FOC= Former ovarian cavity; $\mathrm{B}=$ Brown body; $\mathrm{V}=$ Vas deferens. Scale bar represents $0.5 \mathrm{~mm}$.

to be a rule for labrid species that the secondary structure persists after an ovary has changed into a testis. It is frequently observed in mature secondary testes of other labrid species that the former ovarian lumen becomes narrower and the former ovarian wall becomes thinner. ${ }^{5)}$ All of the secon- dary testes of $C$. azurio studied in the present study had a large lumen and a relatively thick membrane. This may be because the testes were not in the spawning season, but a number of spermatozoa were seen in the vas deferens developed in the former ovarian wall. 
Although yellow bodies can not be adopted as evidence for sex change, ${ }^{7)}$ they were inevitably found at the central part of the testicular lobes of C. azurio (Fig. 1-B).

Mean GSI of the males was $0.172 \pm 0.080(n=6)$ and suggested that the testes were not reproductively active. The GSI value of the secondary males was smaller than that of females, but it is known in many labrid species that the secondary testes are usually smaller than the primary testes or ovaries. ${ }^{4,6)}$

\section{Discussion}

Sadovy and Shapiro ${ }^{\text {7) }}$ presented criteria for the diagnosis of hermaphroditism in fishes. Among these criteria, the present study revealed the sizesex relationship, differences in body color and body form between the males and females, and histological features of the gonads. Among these diagnostic features of Choerodon azurio, the secondary structure of the testes clearly shows that $C$. azurio is a protogynous hermaphrodite, as well as other labrid species. ${ }^{2-s)}$

It was pointed out that the bimodal size-frequency distribution can not be a reliable feature of sex change, because habitat preferences and differential growth can yield the bimodal sizefrequency distribution as well. ${ }^{72}$ Although the present study does not show whether habitat preference and growth differ between the males and females or not, the fact that all the males had secondary testes suggests that the size defference between the sexes of the present species is a result of protogynous hermaphroditism. In the vas deferens of the secondary testes of the present specimens, spermatozoa were already seen (Fig. 1-B). Many spermatozoa and active spermatogenesis were recognized even in the smallest testis (041913 in Table 1). These features may be an indication that the testes were in the process of maturation for the summer spawning season. Because these specimens were collected in spring, spermatozoa found in the vas deferens may not be a residue of the previous spawning season. It is highly probable that individuals found along the northern coast of Kyushu may mature as females when small and then change into males when they grow to nearly $285 \mathrm{~mm} \mathrm{SL}$.

Changes in gender-specific coloration or morphology can be a reliable feature," when it is observed in the same individual. The present study described differences in coloration and morphology between the sexes. Sex-related coloration and morphology of $C$. azurio suggest that the individuals change their coloration and morphology upon sex change.

In spite of a number of studies on sexual patterns of labrid fishes, ${ }^{2-5,8)}$ studies on the subfamily Bodianinae are relatively limited. Sexual patterns of the genus Choerodon are known in only two species, C. albigena and C. transversalis. ${ }^{83}$ The former is a diandric protogynous hermaphrodite but the latter is a monandric one. No primary males occurred in the present specimens and a further study on larger number of specimens is needed before we conclude whether the present species is a monandric or diandric protogynous hermaphrodite.

\section{Acknowledgments}

The authors are deeply indebted to Prof. T. Okuda for his encouragement and advice through the study. We are also grateful to two anonymous reviewers for critical reading of the manuscript.

\section{References}

1) Y. Yamakawa: in "The Fishes of the Japanese Archipelago" (ed. by H. Masuda, K. Amaoka, C. Araga, Y. Ueno, and T. Yoshino), Tokai University Press, Tokyo, 1984, p. 202.

2) R. Reinboth: Zool. Jb. Physiol., 69, 405-480 (1962).

3) R. Reinboth: Mem. Soc. Endocrinol, 18, 515543 (1970).

4) R. R. Warner and D. R. Robertson: Smiths. Contr. Zool., 254, 1-27 (1978).

5) A. Nakazono: Rep. Fish. Res. Lab., Kyushu Univ., No. 4, 1-64 (1979).

6) K. S. Cole and D. R. Robertson: Bull. Mar. Sci., 42, 317-333 (1988).

7) Y. Sadovy and Y. Shapiro: Copeia, 1987, 136156 (1987).

8) Y. Yogo: in "Sex Change in Fishes" (ed. by A. Nakazono and T. Kuwamura), Tokai University Press, Tokyo, 1987, pp. 1-47. 